\title{
Orthorexia: The Dirty Downside of Clean Eating
}

\author{
${ }^{*} J a y a s r i J$
}

\section{Abstract:}

Orthorexia nervosa is one of the eating disorder characterized by an excessive preoccupation with eating healthy food. The direct cause of orthorexia is unknown. Risk Factors for Orthorexia are history of dieting, Low self-esteem, Depression, Anxiety, Obsessive Compulsive Disorder. The main feature of orthorexia is a drive for purity, Weight loss, Malnutrition, Low selfesteem, negative body image. Warning Signs of Orthorexia are Fixation on food quality and purity, rigid segmentation of "healthy" and "unhealthy" foods, highly inflexible eating patterns, Heavy focus on organic, pure and/or raw foods. Treatment includes Psychotherapy, neurofeedback, medication, Exposure and response prevention, Therapies and Hypnosis. Complications include Lowered immune system, Problems with cognition, Osteoporosis, Kidney Failure and Infertility

Key words: Orthorexia and Obsession with Unhealthy foods

\section{INTRODUCTION:}

Eating wholesome, nourishing foods, good to eat healthy food is a worthy goal and eating well is important, any behavior too much of a good thing can nudge toward negative results but what happens when the drive to eat healthy food turns into an obsession is called Orthorexia ${ }^{1}$

Orthorexia nervosa is healthy Obsession or fixation on righteous eating or on food quality and purity. In 1997 American physician Steven Bratman, M.D coined the term Orthorexia. Orthorexia is derived from Greek that means "correct eating."Orthos-"correct or right" and orexia"appetite." is an eating disorder that limits your nutritional options to foods that are considered healthy or clean. He began to used the term with his patient who were overly health obsessed[1,2]

\section{ORTHOREXIA NERVOSA ;}

Orthorexia nervosa is one of the eating disorder characterized by an excessive preoccupation with eating healthy foodand the avoidance of perceived to be unhealthy can lead to a form of dysfunctional eating called Orthorexia nervosa ${ }^{1}$

Person with Orthorexia nervosaexperience physical and emotional health issues, social isolation, anxiety, loss of ability to eat in a natural, intuitive manner, and in severe cases it leads to severe malnutrition or even deathas a result of their desire to maintain a pure diet.

It occurs equally in men and in women, but is most common in middle-class adults who are in the 30-year-old range ${ }^{2}$

\section{CAUSES:}

The direct cause of orthorexia is unknown1 
Risk Factors for Orthorexia ${ }^{[1,2,4]}$

- A history of dieting

- Low self-esteem

- Depression

- Anxiety

- Obsessive Compulsive Disorder (OCD)

- A strong desire to bethin

- An addictive personality

- Perfectionism

- Searching for spiritualitythrough food

- Compulsion for completecontrol

- Escaping from fears

Orthorexic Avoidance Food: A person with orthorexia will be obsessed with defining and maintaining the perfect diet, rather than an ideal weight 3

An orthorexic may avoid numerous foods, including those made with

- Organicfoods that haveno artificial additives

- Foods grown without chemicals of any kind

- Foods that contain no added sugar or salt

- Foods that contain no grain products

- Foods without any naturally occurring fat

Signs and symptoms of Orthorexic The main features of Orthorexia is a "drive for purity" 5

\section{Symptoms of Orthorexia}

- Weight loss

- Malnutrition

- Low self-esteem, negative body image

- Depression, high anxiety

- Social isolation or withdrawal

- Guilt or self-punishment when straying from a "clean" or "healthy" diet

\section{Warning Signs of Orthorexia}

- Fixation on food quality and purity

- Rigid segmentation of "healthy" and 
- Highly inflexible eating patterns

- Heavy focus on organic, pure and/or raw foods

- A high level of attention to planning, purchasing and preparingfood

- Frequent or severe bodycleanses

- Sudden weight fluctuations

- Feelings of satisfaction, esteem, or spiritual fulfillment from eating "healthy"

- Avoiding eating food bought or prepared by others

- Experiencing anger or panic while watching others eat "unhealthy" foods and fear of eating, or even being around "unhealthy" foods

- Feel guilty or anxious when deviating from personal dietaryrestrictions.

- Avoid specific foods due to perceived allergies, often without medical advice or diagnosis

- Noticeable increase in consumption of supplements, herbal remedies or probiotics

- Judging others harshly due to their eating and/or only associating with others who share the same restrictive food rules

\section{Health Risks of Orthorexia[5,6]}

- Malnutrition

- Depression

- Severe anxiety

- Irritability

- mood swings

- In rare cases, death

\section{TREATMENT}

Psychotherapy: cognitive behavior therapy is used for treating OCD. It teaches a person different ways of thinking, behaving, and reacting to situations that help him or her feel less anxious or fearful without having obsessive thoughts or acting compulsively ${ }^{7}$ 
Dialectical Behavior Therapy (DBT) Combines CBT techniques with mindful meditation to help to discover new ways to manage and regulate emotions, identify triggers and work toward changing negative and unhelpful behaviors.7

Family-Based Treatment (FBT) Designed for adolescents, family-based treatment includes parents as active and integral parts of the treatment team. Families help restore weight and a positive adolescent identity in their children as part of a coordinated three-phase approach. ${ }^{8}$

\section{Other}

$\begin{array}{ll}\circ & \text { Individual and GroupCounseling } \\ \circ & \text { Nutritional Counseling } \\ \circ & \text { Expressive Therapy } \\ \circ & \text { Relapse Prevention }\end{array}$

Neurofeedback: Neurofeedback is a form of biofeedback designed to help people alter their brain waves in profound effect on their behavior, mood, and thinking. Neurofeedback provides information about the type and intensity of brain waves involved in areas of brain ${ }^{1}$

Medication: The most commonly prescribed medications for Orthorexia are anti-anxiety medications and antidepressants. 7

\section{Mindfulness Based Cognitive Behavioral} Therapies such as Acceptance and Commitment Therapy (ACT), can help to gain greater awareness and acceptance of uncomfortable thoughts, feelings, sensations and urges related to food and their body and become more aware of conscious of their food consumption $[\cdot 2,7]$

Exposure and Response Prevention (ERP). Gradually introducing a broader variety of foods into the client's diet, including healthy foods that the client has previously decided were unacceptable;
- $\quad$ Restricting, and ultimately eliminating time spent researching food;

- Restricting, and ultimately eliminating time spent discussing the health values of food;

- Returning to normal social interactions, including meals with others.[9,10]

\section{Experential Therapy}

In helps to nurture the mind-body connection and apply in real-world settings. Depending on the client's needs, the following treatment plan works toward overcoming theirorthorexia[7,8]

\begin{tabular}{ll} 
- & Beach trips \\
- & Challenge food outings \\
- & Restaurant outings \\
- & Clothes shopping \\
\hline
\end{tabular}

Hypnosis : Hypnosis is a safe, quick and effective way to overcome compulsions. It helps to reconnect with innate sense of balanced wellness and health and restore your deep human ability to be flexible and adaptive in looking after yourself well. The old rigidities will just melt away.[6,7]

\section{Complications 8}

- Lowered immune system

- Problems with cognition

- Osteoporosis

- Kidney Failure

- Infertility

- Anxiety and stress

- Heart Disease

- Malnutrition

- Social Isolation/ Emotional Instability

\section{References:}

1. American Psychiatric Association. Diagnostic and Statistical Manual of Mental Disorders, 5th ed. Arlington, VA: American Psychiatric Association, 2013

2. Hammond .D.C. (2003). QEEG- guided neurofeedback in the treatment of 
Obsessive compulsive disorder. Journal of neuropathy, 7(2), 25-52.

3. Barclay, R.S. (2015, February 24). Orthorexia: The New Eating Disorder You've Never Heard Of. Healthline News. Retrieved from http://www.healthline.com/healthnews/orthorexia-the-new-eatingdisorder-youve-never-heard-of022415\#1

4. Bratman, S. (2015, May 17). Anxiety and Orthorexia. Retrieved from http://www.orthorexia.com/anxietyand-orthorexia

5. Donini, L.M., Marsili, D., et.al. (2004, June). Orthorexia nervosa: A preliminary study with a proposal for diagnosis and an attempt to measure the dimension of the phenomenon. Eating Weight Disorders. Vol 9: 151-157.
9 Hill, Amelia (16 August 2009). "Healthy food obsession sparks rise in new eating disorder". The Guardian. London. Retrieved 16 October 2010.

10 Bratman, Steven (2014) http://www.orthorexia.com/wh at-is-orthorexia/. Accessed 1/1/2016

11 Rochman, Bonnie (12 February 2010). "Orthorexia: Can Healthy Eating Be a Disorder?". Time. Retrieved 4 January 2012.

12 S. Bratman, D. Knight: Health food junkies. Broadway Books, New York, 2000.

13 Bratman, Steven (2015)http://www.orthorexia.com/hea lthy-eating-vs-orthorexia/Accessed $1 / 1 / 2016$

\title{
ALLEN'S SIGN \\ IN PULMONARY EMBOLISM
}

\section{ALIFN'S SICN}

\author{
F - Fever \\ T - Tachypnea \\ T - Tachycardia
}

